\title{
RESEARCH
}

\section{Social Networking in Medicine: The VIlth Nerve Facebook Page}

\author{
Rachel E. Mullenger ${ }^{1}$, Lauren H. Jain ${ }^{2}$, Nadim Joukhadar ${ }^{3}$, Genna Bourget ${ }^{4}$, Ehud Ur MD FRCP5, \\ Kim Blake MD FRCPC ${ }^{6}$ \\ 'Class of 2015, Faculty of Medicine, Dalhousie University \\ ${ }^{2}$ Class of 2013, Faculty of Medicine, Dalhousie University \\ ${ }^{3} \mathrm{BSC}$ canditate, McGill University \\ ${ }^{4} \mathrm{MD}$ canditate, University College Dublin \\ ${ }^{5}$ Division of Endocrinology, Department of Medicine, University of British Columbia \\ ${ }^{6}$ Department of Pediatrics, Dalhousie University
}

\begin{abstract}
Background: Social networks including Facebook are gaining popularity in industry, however, health care has yet to fully embrace this trend. Social networking enables unprecedented speed and scope of communication and information sharing; mobile devices allow health professionals to feel connected to training hospitals, peers and mentors. The VIlth Nerve is a Facebook page for medical students worldwide, providing a platform to share medical cases, educational videos and audio sounds.

Methods: A Facebook page was developed and is ongoing. A research team has been established to design and run the page, and collect data. Demographics, location of users, visits to the page, type of posts and total number of users were tracked.
\end{abstract}

Results: To date, 161 users subscribed to the Facebook page and a total of 44,042 people have been reached. Sixtyfour per cent of subscribers are female, 89 per cent of whom fall between the ages of 18 and 34 . Users are from nine countries and eight different first languages are indicated. It has been found that users are most engaged by visual materials, namely videos clips and photos.

Conclusion: Synergies between social networks and medicine is vastly underrepresented in the literature to date. Implications of social media in the learning environment may be of significant value and affect the future practice of medicine. Future steps will include focus groups to recognize the benefits and pitfalls of using Facebook in the health care setting. This research effectively connects students internationally, and will determine how social media can effectively be implemented to prepare students for life-long learning.

In today's technological society, the implications of social media in the learning environment may be of significant value and affect the future practice of medicine; however, synergies between social networks and medicine are underrepresented in the social media and medical literature. Today's society has seen a revolution in technology and a rise in the popularity of social network platforms, including Facebook. Facebook was created in 2004 and is now the largest social media network worldwide. ${ }^{1}$ Facebook has a network of 750 million users. ${ }^{2}$ Social media is a valuable tool in connecting individuals worldwide while enabling unprecedented speed and scope of communication and information sharing. Social networking sites are popular online communication forums that allow individuals to engage with others over the Internet. ${ }^{3}$ A recent study of university students found that $25 \%$ of students used Facebook for educational purposes and $66 \%$ were open to its use for this purpose. ${ }^{4}$ There is much interest in social media despite the term being poorly defined. ${ }^{5}$ Blogs, social networking sites, mobile apps, podcasts and online magazines all fall into the category of social media. A study by Cain \& Policastri, chose Facebook as the medium to introduce social media as an informal learning strategy because it was a simple means to share information, discussions could easily be followed and it was a feasible method to connect students with peers and experts. ${ }^{6}$

Today's new generation of clinicians appear keen to adopt social media. As they enter their medical careers, social media has the potential to have a strong impact on medicine. A number of studies in the literature have investigated the use of mobile devices in both undergraduate and graduate medical education., ${ }^{4-20}$ In a US study of cell phone use in medical students, $94 \%$ of third-year medical students at a Midwestern University 
used text messaging and $76.9 \%$ used the Internet on their mobile devices. ${ }^{20}$

The introduction of social media into medicine has seen mixed results, with most areas of conflict revolving around confidentiality. ${ }^{2}$ A major concern about the use of social media by health professionals and medical students is the publication of unauthorized and unprofessional materials that have the potential to breach patient confidentiality. ${ }^{2}$ For example, with the use of social media, physicians are able to post about patient cases. Without obtaining authorized consent from the patient to do so, this information could lead to potential disclosure of patient's personal information and break confidentiality.

The shift from the Internet as a content management tool to a social media platform began in 2005; today, the majority of students are well connected with mobile smart phones, tablets and laptops that allow quick access to countless resources at their fingertips. ${ }^{21}$ Social media is generally cost effective and relatively easy to use. Mobile devices can be taken anywhere, providing the potential for "anytime, anywhere" learning experiences. Additionally, students in remote areas can feel connected to larger training hospitals, as well as to their peers, tutors and mentors. ${ }^{9}$

Although social media is on the rise, health care is one of the last industries to embrace the trend, with only $9.58 \%$ of US hospitals reportedly using social media. ${ }^{21}$ Social media resources appear to have great potential in medical education; however, there is a lack of concrete information to demonstrate their potential benefits. ${ }^{22}$ In the past four years, the use of social media has rapidly increased, and medical students, residents and clinicians have adopted this trend. Between 64-96 $\%$ of health science students have a Facebook account whereas only 13-47 \% of professional clinicians hold an account. ${ }^{2}$ According to a study of health professional students, ${ }^{23}$ the majority of students were using Facebook and preferred it to other social networking sites. The study also found that students preferred online resources as their primary source of information. ${ }^{23}$

The VIIth Nerve Facebook page was created for medical students worldwide to centralize resources and facilitate peer-communication and networking. Although intended for medical trainees, the site is a resource for health professionals in all specialties. The page currently has open access, but the option is available to change the security settings so that authorization is mandatory. The page is capable of sharing medical cases and educational tools such as videos, apps, audio, and research articles. The page was designed to foster a convenient ground for peer communication and ultimately self-development and achievement in the medical profession. In today's fast-paced and technologically advanced society, learning resources such as textbooks can quickly become outdated. Thus, the idea behind designing this page was to allow students to have access to up-to-date materials, while additionally providing the opportunity for students to engage with peers worldwide and share experiences, feedback and pose questions to others. Materials are currently uploaded by members of the editorial board and anyone who subscribes to the page has the ability to make a post. The editorial board is notified of each post and has the ability to remove the post immediately if the content is invalid or inappropriate. It seems appropriate to incorporate a simple program, that is already a part of students' daily routine, into students' learning rather than overload the number of resources. Subscribers to the VIIth Nerve Facebook page will be notified as new posts and resources are uploaded allowing for immediate access.

The purpose of this study is to determine the degree of acceptability of Facebook as a form of resource and education sharing tool in the medical community. The capability of Facebook to effectively enhance clinical teaching and learning will be explored through the VIIth Nerve Facebook page and focus groups. The advantages and disadvantages of using Facebook in medical education will also be examined. The goal is to increase knowledge and insight into the tools that students find beneficial throughout their undergraduate medical education and delineate how social media can effectively be implemented to prepare students for clinical clerkship and life-long learning.

\section{Process}

A Facebook page was developed and input is ongoing. An editorial board, with international members, runs the site: the interactive nature allows students to shape the content and materials displayed on the site. Members of the editorial board include one physician from each of Dalhousie University, University of British Columbia, and RWTH Aachen University, Germany. The board also includes medical students from Dalhousie University, McGill University, and UCD Ireland. Members of the board post resources including cases, videos, photos, tools, innovative research, and news articles on a regular basis. All users are capable of commenting on posts as well as posting their own materials to share with others. 
Demographics and location of users, visits to the page, type of posts and total number of users were tracked by a member of the editorial board through Facebook and analyzed. The types of media viewed and posted by users were compared. Conclusions can be drawn regarding the most popular types of media. Users were tracked directly on the Facebook page and accessed by members of the editorial board who have been granted administration privileges. This provides information on the number of new visits to the page, as well as the number of times users returned to the page. The numbers of comments or "likes" for each post were recorded.

To date 161 users have subscribed to the Facebook page and a total of 44,042 people have been reached through Facebook. Sixty-four per cent of subscribers identified themselves as female and $34 \%$ identified themselves as male (Figure 1). Eighty-eight per cent fell between the ages of 18 and 34. Users who subscribed to the page were from 11 countries, 20 different cities and four different first languages were indicated. Visits to the site were tracked per day and per week on Facebook and accessed by the editorial team. On average, 360 students were reached per week, with 40-200 people being reached per post. A "like" indicated someone has subscribed to the page. Seven per cent of "likes" were from a mobile phone, seven per cent of "likes" were by clicking on a link from someone else's post and $85 \%$ of the "likes" were directly from the VIIth Nerve page. The number of unique page views and the number of people talking about the page increased proportionately to the number of posts and the timing of the posts. In a three month period, 193 new users visited the page. Fortythree new users returned to the page twice and 54 people viewed the page greater than 10 times (Figure 2).

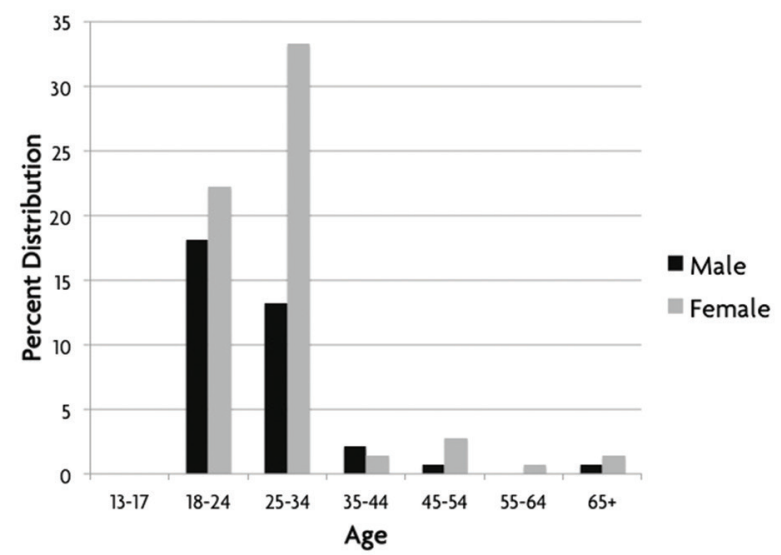

Figure 1. Gender and age of users using the VIIth Nerve Facebook page.

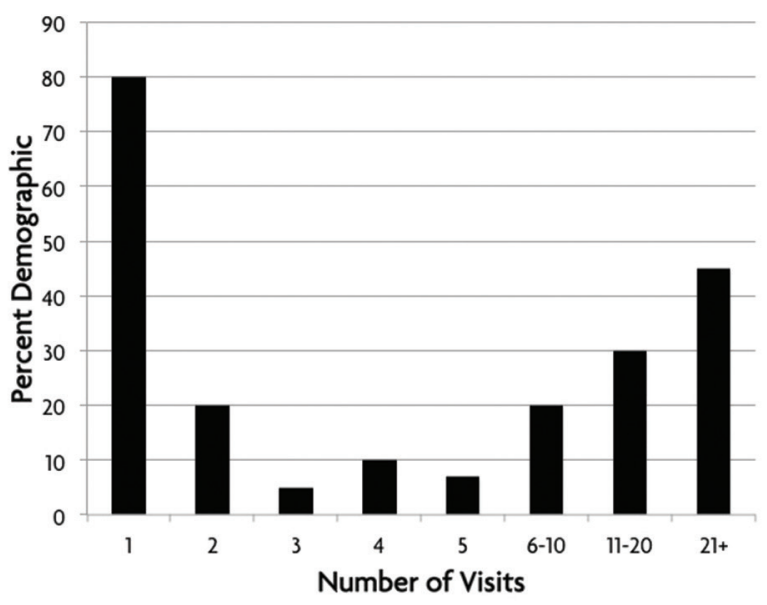

Figure 2. Frequency of visits to page per user.

\section{Discussion}

The VIIth Nerve is in its infancy, but it has captured students' attention and has successfully recruited an international following.

Users were most engaged by videos and photos, while questions and polls had the least interaction, possibly due to confidentiality and anonymity. When questions and polls are posted to the page, the number of poll views did not correspond to the number of poll responses. This suggests that students are interested in the content but a potential reason for not responding may be confidentiality issues due to the fact that others can view their answers and account profile. When users respond to the polls, their picture appears in association with their answer. It is hypothesized by the research team that more people would be willing to participate if their picture/name were not included.

Medical students and residents' sense of professionalism is developing and they may not understand the publicly available content they publish on their Facebook profile directly reflects their level of professionalism. ${ }^{24}$ The boundaries between personal and professional are beginning to blend in today's younger, social media savvy generations. Personal information that medical students would not normally reveal to patients or colleagues is accessible through their Facebook pages. ${ }^{24}$ In a study by Garner \& O'Sullivan, $52 \%$ of respondents admitted to having photos on their Facebook profile they found embarrassing and $54 \%$ of respondents had seen unprofessional behavior by their colleagues on Facebook. ${ }^{25}$ Facebook users have the option of applying privacy settings to their account and, medical professionals should accept the responsibility and accountability of maintaining professionalism. To deal with the issue of patient confidentiality and 
professionalism while using social media, an editorial board has been established and closely monitors the content of the VIIth Nerve Facebook page. Members of the editorial board obtained verbal consent from patients prior to any photos, videos or personal information being posted on the site. When others post information, the editorial board confirms that consent has been obtained. In the event that any unprofessional content is posted, members of the editorial board have the ability to remove the material from the page. To date, there have been no issues with the content posted on the Facebook page and no posts have been altered or removed.

A potential downside to the page is that older posts are not easily accessible or neatly organized in categories. A user must scroll through all past posts when looking for a particular post or subject matter, unlike a website with organized links to categories. The editorial board is taking steps to add categories to the page so users can easily go to an area of interest such as pediatrics, obstetrics or surgery. A more streamlined website, outside of Facebook, has been designed to address this issue. This website will create a space to archive all posted information in categories that are easily navigated and link seamlessly to the Facebook page itself. Another struggle of the page is encouraging students to post information, moving away from a one-sided resource, as well as increasing the self-sustaining nature of the page. We believe this will happen in a snowball effect as the site continues to grow.

We plan to expand the scope of the VIIth Nerve page by including more schools across Canada and internationally. As the audience grows and users become more engaged, we anticipate that the page will become increasingly self-sustainable. We will augment the role of the editorial board, much in a similar way to that of a journal, to evaluate page content, monitor material and encourage users.

\section{Ongoing Evaluation}

Focus groups will be conducted to determine usefulness and challenges of social media in education, and to enhance the data generated by users. The objectives of the focus groups will be to learn how students use social media, and to highlight the benefits and pitfalls of Facebook in the health care setting. Focus groups will aim to gather information on the types of materials students find most useful and identify how the page can be improved to best meet the needs of students. Questions will focus in general on the potential of social media in medical education, specifically on the VIIth Nerve Facebook page. Focus groups will be recorded and transcribed. Transcriptions will then be coded and analyzed for themes. The VIIth Nerve page will continue to grow its network of student users worldwide and adapt to meet the needs of its audience.

\section{Conclusion}

The VIIth Nerve page is evolving and has effectively connected students internationally. This research will contribute to the literature on social media in medical education, and offer insight into applicability and enhancement of traditional means of education and resource sharing. This research has the potential to affect the future practice of medicine, and will determine how social media can effectively be implemented to prepare students for clinical clerkship. Additionally, it has the potential to act as a resource throughout physicians' careers. We invite you to visit our page, explore the resources posted to date, and encourage you to share your favorite medical apps, articles, etc. with other health professionals worldwide. You can subscribe to the VIIth Nerve page by visiting www.facebook.com/ VIIthnerve.

\section{Reference}

1. Mena G, Llupià A, García-Basteiro AL, Aldea M, Sequera VG, Trilla A. The willingness of medical students to use Facebook as a training channel for professional habits: the case of influenza vaccination. Cyberpsychol Behav Soc Netw 2012;15(6):328-31.

2. von Muhlen M, Ohno-Machado L. Reviewing social media use by clinicians. J Am Med Inform Assoc 2012;19(5):777-781.

3. Subrahmanyam K, Reich SM, Waechter N, Espinoza G. Online and offline social networks: Use of social networking sites by emerging adults. J Appl Dev Psychol 2008;29(6), 420-433.

4. Kennedy G, Gray K, Tse J. 'Net Generation' medical students: Technological experiences of pre-clinical and clinical students. Med Teach 2008;30:10-16.

5. Kaplan AM, Haenlein M. Users of the world, unite! the challenges and opportunities of social media. Business Horizons 2010;53(1): 59-68.

6. Cain J, Policastri A. Using Facebook as an informal learning environment. Am J Pharm Educ 2011;75(10):207.

7. Bahner DP, Adkins E, Patel N, Donley C, Nagel R, Kman NE. How we use social media to supplement a novel curriculum in medical education. Med Teach 2012;34(6):439-444.

8. Barrett JR, Strayer SM, Schubart JR. Assessing medical residents' usage and perceived needs for personal digital assistants. Int J Med Inform 2004;73:25-34.

9. Boulos MN, Maramba I, Wheeler S. Wikis, blogs, and podcasts: A new generation of web-based tools for virtual collaborative clinical practice and education. BMC Med Educ 2006;6:41.

10. Sutton J, Stockton L, McCord G, Gilchrist VI, Fedyna D. Handheld computer use in a family medicine clerkship. Acad Med 2004;79:1114-1119.

11. Mattana J, Charitou M, Mills L, Baskin C, Steinberg H, Tu C, Kerpen H. Personal digital assistants: A review of their application in graduate medical education. Am J Med Qual 2005;20:262-267.

12. Khan BH. Flexible Learning in An Information Society. Information Science Publishing 2007. 